\title{
Development of a Measure of Workplace Deviance
}

\author{
Rebecca J. Bennett \\ University of Toledo
}

\author{
Sandra L. Robinson \\ University of British Columbia
}

\begin{abstract}
The purpose of this research was to develop broad, theoretically derived measure(s) of deviant behavior in the workplace. Two scales were developed; a 12-item scale of organizational deviance (deviant behaviors directly harmful to the organization) and a 7-item scale of interpersonal deviance (deviant behaviors directly harmful to other individuals within the organization). These scales were found to have internal reliabilities of .81 and .78 , respectively. Confirmatory factor analysis verified that a 2 -factor structure had acceptable fit. Preliminary evidence of construct validity is also provided. The implications of this instrument for future empirical research on workplace deviance are discussed.
\end{abstract}

Workplace deviance is a pervasive and expensive problem for organizations. For example, $75 \%$ of employees have reportedly stolen from their employer at least once (McGurn, 1988), and it has been estimated that $33 \%$ to $75 \%$ of all employees have engaged in behaviors such as theft, fraud, vandalism, sabotage, and voluntary absenteeism (Harper, 1990). In recent studies, almost $25 \%$ of an employee sample indicated knowledge of illicit drug use among coworkers during the past year (Lehman, Wolcom, \& Simpson, 1990), $42 \%$ of a surveyed sample of women reported experiencing sexual harassment at work (Webb, 1991), and 7\% of a sample of employees reported being victims of physical threats (Northwestern Life Insurance Company, 1993).

It is not surprising that the prevalence of workplace deviance poses a serious economic threat to organizations. The annual costs of workplace deviance have been estimated to be as high as $\$ 4.2$ billion for workplace violence alone (Bensimon, 1994), $\$ 40$ to $\$ 120$ billion for theft (Buss, 1993; Camara \& Schneider, 1994), and $\$ 6$ to $\$ 200$ billion for a wide range of delinquent organizational behavior (Murphy, 1993).

Despite the prevalence and costs of workplace deviance, our current understanding of workplace deviance remains limited, and much empirical research has yet to be done. This empirical research may be enhanced by the availability of a validated measure of workplace deviance. The purpose of this study is to produce such a measure.

Rebecca J. Bennett, Department of Management, University of Toledo; Sandra L. Robinson, Faculty of Commerce and Business Administration, University of British Columbia, Vancouver, British Columbia, Canada.

Support for this research was provided by an Academic Challenge Grant Award from the Department of Management at the University of Toledo. We thank Lynn Shore, Paul Spector, and Linn Van Dyne for their helpful advice.

Correspondence concerning this article should be addressed to Rebecca J. Bennett, Department of Management, University of Toledo, Toledo, Ohio 43606-3390. Electronic mail may be sent to rebecca.bennett@ utoledo.edu.

\section{Understanding Workplace Deviance}

Workplace deviance has been defined as voluntary behavior that violates significant organizational norms and, in so doing, threatens the well-being of the organization or its members, or both (Robinson \& Bennett, 1995). Workplace deviance refers to voluntary behavior in that employees either lack motivation to conform to, and/or become motivated to violate, normative expectations of the social context (Kaplan, 1975). Organizational norms consist of basic moral standards as well as other traditional community standards, including those prescribed by formal and informal organizational policies, rules, and procedures (Feldman, 1984).

For scales to be valid, it is essential that there be at least a tentative theoretical model to guide scale development (Churchill, 1988; DeVellis, 1991). It is argued here that deviant behaviors fall into clusters or families (Robinson \& Bennett, 1997; Roznowski \& Hulin, 1992). Any specific deviant behavior can be placed into one of these behavioral families. We make this assumption because we believe that although there are a myriad of different manifestations of deviant behaviors, research suggests that some of these manifestations are similar in nature to one another, share similar antecedents, and may thus be functional substitutes for one another (i.e., they serve the same goals; Robinson \& Bennett, 1997).

Research suggests a wide range of reasons why employees engage in deviant behavior (Bennett, 1998a, 1998b; Robinson \& Bennett, 1997; Robinson \& Greenberg, 1999), ranging from reactions to perceived injustice, dissatisfaction, role modeling, and thrill-seeking. Yet, deviant organizational behavior is distinct in that it is usually behavior that is very constrained in the workplace. Employees in a given time period or context are very limited in terms of the type of deviant behavior in which they can engage. Thus, they may be motivated to engage in deviance, but that deviance will take different manifestations depending on the constraints of the situation. We would argue then that an employee may choose from among deviant behaviors within a family that are functionally equivalent, choosing the one that is least constrained, most feasible, or least costly, given the context (Robinson \& Bennett, 1997).

If an individual engages in one behavior from a family, he or she is more likely to engage in another behavior from that family than 
to engage in a behavior within another family. We assume employees may engage in behavioral switching within families because the behaviors within each are substitutable and functionally equivalent (Robinson \& Bennett, 1997). Employees then may engage in one or several behaviors from a wide set.

If we apply the family of behavior metaphor to deviant behaviors, what might those families of deviance look like? Robinson and Bennett $(1995,1997)$ identified a typology of workplace deviance that may provide insight into this question. They argued that an important distinction between types of deviance was whether the deviance was directed or targeted at either the organization (organizational deviance) or at members of the organization (interpersonal deviance). The target of deviance is an important element of deviance for several reasons. First, it is posited that this dimension of deviance identifies an important qualitative difference between deviant acts; individuals prone toward deviance directed at the organization are likely to be different than those individuals prone toward deviance directed at other individuals. Numerous behavioral constructs, from conflict to dissatisfaction behavior to citizenship behavior, have been classified in terms of their targets (C. D. Fisher \& Locke, 1992; Organ, 1988, 1990; Roznowski \& Hulin, 1992; Williams \& Anderson, 1991). The domain of workplace deviance is no exception. Most conceptual approaches to workplace deviance have explicitly acknowledged that deviance may be directed at either the organization itself or its members, or both (Baron \& Neuman, 1996; Giacalone \& Greenberg, 1997; O'Leary-Kelly, Griffin, \& Glew, 1996; Robinson \& Greenberg, 1999; Skarlicki \& Folger, 1997). Both Green (1997) and Turner and Stephenson (1993) have conceptualized organizational crimes in terms of targets. A similar distinction has been drawn regarding conceptualizations of more specific types of deviant acts as well. For example, Greenberg and Scott (1996) have distinguished between employee theft directed at other employees (e.g., taking money from a coworker's wallet) and that directed at the organization (e.g., taking money from the cash register). Using the above example, it makes sense to avoid referring to both behaviors as forms of theft (e.g., Snyder, Blair, \& Arndt, 1990) and attempting to interpret them in a similar fashion. Indeed, despite similarities between them, there is good reason to believe that these two forms of deviance are motivated by different factors (Bies, Tripp, \& Kramer, 1997; Giacalone, Riordan, \& Rosenfeld, 1997).

Robinson and Bennett (1997) also noted that deviance may vary along a continuum of severity, from minor forms of deviance to more serious forms. Unlike the interpersonal versus organizational distinction, however, this is more a quantitative distinction rather than a qualitative one. Thus, although one would expect that interpersonal and organizational deviance would fall into distinct clusters or families representing two qualitatively different forms of deviance, both families of deviance contain both serious and minor forms of deviance. Serious and minor deviant behaviors would not, by themselves, reflect two different types of deviance. Thus, for example, both spreading rumors and physical violence would fall into the interpersonal deviance family, just as both sabotaging equipment and littering one's work environment would fall into the organizational deviance family. This distinction is analogous to individual items on an achievement test. Items on the test vary qualitatively in terms of knowledge content area (e.g., spelling vs. math items) and quantitatively in terms of difficulty within each content area, just as the items on our deviance scale vary in terms of the type of deviance represented as well as their seriousness. A summation of items reflecting each type of deviance should indicate the participation levels of each form of deviance, much like summing the numbers of math items versus spelling items would indicate the knowledge level in those different areas.

Given the above, we propose that workplace deviance can be captured with two general factors: interpersonal deviance and organizational deviance (both serious and minor forms of each type are represented within each family).

\section{Present Study}

To develop a measure of workplace deviance, three multiphase studies were conducted. In the first study, a pool of 314 deviant workplace behaviors was generated and these behaviors were reviewed and assessed by a panel of experts. In the second study, a subset of 58 of the deviant behavior items was further refined to 23 items by analyzing the interitem correlations, variances, and factor loadings of each item. Finally, a third study was conducted using confirmatory factor analysis (CFA) to verify the proposed dimensionality of the remaining 23 items and to begin the process of construct validation.

\section{Study 1: Instrument Development}

\section{Phase 1: Item Generation}

The purpose of this phase of the study was to create a large, inclusive pool of exemplars of deviant behavior, so that together they reflect the domain of behaviors meeting our definition of workplace deviance. Consistent with this purpose, types of deviant behaviors were generated in a variety of ways. Two separate samples of employees were asked for examples of various forms of workplace deviance. Previous research and theory were also examined for further examples of behaviors that fit our definition of workplace deviance. From these sources, an initial pool of 314 examples of deviant behaviors was obtained, taking into account considerable redundancy.

Procedure 1. We recruited 70 respondents from four sources in Toledo, Ohio: a university office $(n=7)$, a technical staff office within an industrial company ( $n=10)$, a neighborhood $(n=38)$, and an evening masters of business administration (MBA) class $(n=15)$. All of the respondents worked full time. Of the participants, $61 \%$ were women. These employees had an average age of 37 years $(S D=14.69)$ and had worked an average of 15.69 years $(S D=12.10)$.

Respondents were asked to describe two incidents of "someone at work engaging in something considered to be deviant at their workplace (i.e., something that is considered to be wrong)." A total of 45 unique behaviors were generated in this manner.

Procedure 2. In all, 62 upper-level undergraduate students also provided examples of workplace deviance that they had observed or experienced. Their average age was 24 years $(S D=5.47)$, and $42 \%$ were women. All worked at least $20 \mathrm{hr}$ per week in a variety of jobs, such as retail clerks, bank tellers, waitstaff, sorters and loaders for a major shipping company, managers for small and large companies, clerical positions, and child 
care. Respondents reported an average of 6.46 years of work experience $(S D=5.48)$.

Respondents were asked to describe an example of each type of deviant workplace behavior that Robinson and Bennett (1995, $1997)$ identified. From this procedure, 45 unique behaviors were generated.

Procedure 3. The researchers also independently generated 68 items on the basis of 23 previously published theoretical and empirical investigations of deviant behaviors in the workplace. After eliminating redundant behaviors, 113 examples of deviant behaviors in organizations remained.

\section{Phase 2: Item Review}

Sample. The 113 items were reviewed by nine judges with different but related areas of expertise: industrial psychology, labor relations, marketing, organizational behavior, strategic management, and organizational communication. Seven of the judges were academics with a doctoral degree and management consulting experience, and the remaining two judges were practicing managers.

Procedure. The judges reviewed the items on the basis of several criteria. First, the judges rated each behavior in terms of whether it was consistent with the definition of deviance used here; that is, whether the item reflected behavior that is voluntary; behavior that is potentially harmful to organizations or its members, or both; and behavior that would violate significant norms in most organizations. Second, the judges rated each behavior in terms of its clarity and consciousness. Third, the judges rated the degree to which each item reflected a behavior that would be relevant to a wide variety of occupations and organizations. Judges used a 7-point Likert scale ranging from 1 (strongly disagree) to 7 (strongly agree) to rate the behaviors on each of these criteria. Items that received a mean score of 3.0 or less on any of the rating dimensions were either rewritten or eliminated. As a result of this process, 58 items survived.

\section{Study 2: Instrument Refinement}

\section{Sample}

A total of 226 respondents participated in Study 2. Of these respondents, 126 were full-time employees and 100 were MBA students. Inasmuch as the MBA students were entering their first term in the program, all had worked full time a few months prior to their participation. The average age (for the combined sample) was 28.3 years $(S D=7.09)$, the average years of work experience was $7.14(S D=6.40)$, and they had worked an average of 44.73 $(S D=12.51)$ hr per week. Of the respondents, $44 \%$ were women. The respondents worked in the following industries: retail (19.5\%), manufacturing (11.5\%), public or government service $(10.2 \%)$, hotel and restaurant $(5.3 \%)$, education $(4.4 \%)$, and other service industries $(45.6 \%) ; 3.5 \%$ did not report the industry in which they worked. Respondents worked in the following occupations: professional (19\%), service provider (18\%), manager $(16 \%)$, technician $(15 \%)$, clerical $(12 \%)$, sales $(11 \%)$, crafts/repair $(3 \%)$, and production (1\%).

\section{Procedure}

Professors who were not involved in the research asked their students to participate. A graduate student briefly explained that the surveys were both voluntary and completely anonymous. Students were given $20 \mathrm{~min}$ of class time to complete the survey.

The nonstudent respondents were approached by a graduate student, who briefly explained that a professor at the university was conducting research on attitudes and behaviors at work and would appreciate their completion of a brief survey. Because no names or code numbers were associated with the surveys, respondents were assured that their responses were anonymous.

The survey was composed of a list of the 58 deviant workplace behavior items. Respondents were asked to indicate on a 7-point Likert scale the extent to which they had engaged in each of the behaviors in the last year. The scale anchors were as follows: 1 (never), 2 (once a year), 3 (twice a year), 4 (several times a year), 5 (monthly), 6 (weekly), and 7 (daily). Respondents also answered several demographic questions.

\section{Phase 1: Item Selection Process}

Evaluation of items was made on the basis of two criteria: item-total correlations and item variances. Because a scale should be composed of highly interrelated items (DeVellis, 1991), items with high interitem correlations with items theorized to be in the same behavioral family were selected to be included in the subscales. The variance of the workplace deviance items was also considered in determining which items to select for the scales. Because items with extremely low variances do not allow discrimination between individuals on the construct of interest (DeVellis, 1991), items with variances below 1.5 were eliminated. This process resulted in the removal of 30 items, leaving us with 28 . The means, standard deviations, and participation rates for these 28 items are presented in Table 1 . It is noteworthy that 19 of the 28 behaviors had participation rates of $50 \%$ or more, indicating that $50 \%$ or more of the respondents had engaged in those behaviors in the last year.

\section{Phase 2: Preliminary Factor Analysis}

We conducted a principal factor analysis to analyze the interrelationships of the items and to suggest additional items for deletion (Ford, MacCallum, \& Tait, 1986; Schwab, 1980). Our guiding theory suggested two related forms of workplace deviance, and hence, we used a principal axis factoring procedure with oblique rotation to impose a two-factor solution (Ford et al., 1986; Kim \& Mueller, 1978). In order to ensure that each item represented the construct underlying each factor, we used a factor weight of .40 as the minimum cutoff. Second, we required each item to be clearly defined by only one factor and, thus, maintained that the difference between weights for any given item was more than .10 across factors. Four items were dropped because they did not meet these criteria, thus 24 items remained. As shown in Table 2, these two factors appear to represent interpersonal and organizational forms of deviance. From these results, we developed two scales: One labeled Organizational Deviance was composed of 16 items, and one labeled Interpersonal Deviance was composed of 8 items. 
Table 1

Means, Standard Deviations, and Participation Rates of Deviant Workplace

Behaviors in Study 2

\begin{tabular}{llll}
\hline \multicolumn{1}{c}{ Item } & $M$ & $S D$ & Participation rate $^{\mathrm{a}}$ \\
\hline $\begin{array}{l}\text { 1. Worked on a personal matter instead of work for your } \\
\text { employer }\end{array}$ & 4.40 & 1.96 & 84.3 \\
2. Taken property from work without permission & 2.39 & 1.69 & 51.8 \\
3. Spent too much time fantasizing or daydreaming instead of & 4.00 & 2.11 & 77.4 \\
$\quad$ working & & & \\
4. Made fun of someone at work & 4.29 & 2.29 & 77.8 \\
5. Falsified a receipt to get reimbursed for more money than & 1.69 & 1.34 & 24.6 \\
$\quad$ you spent on business expenses & & & \\
6. Said something hurtful to someone at work & 2.40 & 1.60 & 55.2 \\
7. Taken an additional or a longer break than is acceptable at & 3.95 & 1.98 & 78.5 \\
your workplace & & & \\
8. Repeated a rumor or gossip about your company & 3.66 & 1.91 & 72.5 \\
9. Made an ethnic, religious, or racial remark or joke at work & 2.69 & 1.96 & 52.5 \\
10. Come in late to work without permission & 3.39 & 1.91 & 70.0 \\
11. Littered your work environment & 1.97 & 1.80 & 28.5 \\
12. Cursed at someone at work & 2.73 & 2.09 & 50.5 \\
13. Called in sick when you were not & 2.30 & 1.36 & 57.8 \\
14. Told someone about the lousy place where you work & 2.93 & 1.99 & 58.9 \\
15. Lost your temper while at work & 3.44 & 1.82 & 78.8 \\
16. Neglected to follow your boss's instructions & 2.78 & 1.78 & 60.6 \\
17. Intentionally worked slower than you could have worked & 2.71 & 1.90 & 54.1 \\
18. Discussed confidential company information with an & 1.90 & 1.51 & 33.3 \\
unauthorized person & & & \\
19. Left work early without permission & 2.65 & 1.84 & 51.9 \\
20. Played a mean prank on someone at work & 1.94 & 1.56 & 35.7 \\
21. Left your work for someone else to finish & 2.21 & 1.52 & 48.6 \\
22. Acted rudely toward someone at work & 2.70 & 1.85 & 53.0 \\
23. Repeated a rumor or gossip about your boss or coworkers & 3.60 & 1.87 & 69.1 \\
24. Made an obscene comment at work & 2.81 & 2.23 & 48.4 \\
25. Used an illegal drug or consumed alcohol on the job & 1.70 & 1.44 & 25.9 \\
26. Put little effort into your work & 2.94 & 1.84 & 64.0 \\
27. Publicly embarrassed someone at work & 1.84 & 1.43 & 33.9 \\
28. Dragged out work in order to get overtime & 1.77 & 1.48 & 26.0 \\
\hline
\end{tabular}

Note. Responses ranged from 1 (never) to 7 (daily). $N=226$.

${ }^{a}$ Percentage of respondents who indicated that they had participated in the behavior at least once in the last year.

\section{Study 3: Instrument Validation}

\section{Sample}

Two samples were used. One larger sample $(n=352)$ was used for the purposes of CFA, and a subset of that sample $(n=133)$ was used for the purposes of preliminary construct validity testing. Thus, the larger sample provided self-reports of their deviant behavior, whereas the subsample provided both self-reports of their deviant behavior and self-reports of other constructs. The reason for this split was to balance our need to obtain a sufficiently large sample to conduct CFA with our need to keep the survey as short as possible so as to increase our response rate. Descriptive statistics of these samples are provided below (the statistics in parentheses apply to the subsample).

The sample was composed of 352 (133) full-time employees from the Toledo, Ohio, area. Of the respondents, $44 \%$ (49\%) were women. Average age was 43.51 years $(S D=10.5 ; 43.58$ years, $S D=10.94$ ). The education level of the respondents varied: $29 \%$ (27\%) had only high school level education, 39\% (37\%) had some college training, $23 \%(28 \%)$ had a bachelor's degree, and $9 \%(8 \%)$ had a graduate degree. Average years of work experience for this sample was $23.41, S D=10.17(23.52, S D=10.57)$. Annual income ranged from under $\$ 10,000$ to above $\$ 100,000$, with the mode being a salary between $\$ 15,000$ and $\$ 30,000$. Occupational titles of these respondents were as follows: $26 \%$ (26\%) professionals; $15 \%(16 \%)$ managers, $9 \%(9.2 \%)$ clerical workers, $8 \%$ (10.7\%) production workers, $8 \%(6.1 \%)$ service providers, $7 \%$ (5.3\%) technicians, $6 \%(6.1 \%)$ salespersons, and $4 \%(4.6 \%)$ craftsmen or repairmen; $16 \%(16 \%)$ did not specify their occupational title.

\section{Procedure}

A total of 1,000 individuals were chosen from the Toledo, Ohio, area phone directory using a systematic random sampling procedure (Fowler, 1993). In order to maximize our response rate, we followed most of the recommendations put forth by Dillman's $(1972,1978)$ total design method. Each potential respondent was mailed a cover letter, a survey, and a self-addressed stamped envelope to their home address. A follow-up postcard was sent 2 weeks after the survey to encourage participation. Another letter, survey, and self-addressed stamped envelope were mailed 4 weeks after the initial survey was sent.

All of the respondents were given a survey that included a list of the 24 deviant workplace behaviors. Respondents were asked to 
Table 2

Principal Axis Factor Analysis (Oblimin Rotation)

\begin{tabular}{|c|c|c|}
\hline \multirow[b]{2}{*}{ Item } & \multicolumn{2}{|c|}{ Factor loadings } \\
\hline & $\begin{array}{l}\text { Organizational } \\
\text { deviance }\end{array}$ & $\begin{array}{l}\text { Interpersonal } \\
\text { deviance }\end{array}$ \\
\hline 1. Worked on a personal matter instead of work for your employer & .50 & .23 \\
\hline 2. Taken property from work without permission & .56 & .33 \\
\hline $\begin{array}{l}\text { 3. Spent too much time fantasizing or daydreaming instead of } \\
\text { working }\end{array}$ & .61 & .38 \\
\hline 4. Made fun of someone at work & .32 & .71 \\
\hline $\begin{array}{l}\text { 5. Falsified a receipt to get reimbursed for more money than you } \\
\text { spent on business expenses }\end{array}$ & .43 & .16 \\
\hline 6. Said something hurtful to someone at work & .26 & .57 \\
\hline $\begin{array}{l}\text { 7. Taken an additional or a longer break than is acceptable at your } \\
\text { workplace }\end{array}$ & .68 & .37 \\
\hline 8. Repeated a rumor or gossip about your company & .65 & .54 \\
\hline 9. Made an ethnic, religious, or racial remark or joke at work & .25 & .55 \\
\hline 10. Come in late to work without permission & .66 & .41 \\
\hline 11. Littered your work environment & .45 & .19 \\
\hline 12. Cursed at someone at work & .38 & .63 \\
\hline 13. Called in sick when you were not & .49 & .44 \\
\hline 14. Told someone about the lousy place where you work & .48 & .36 \\
\hline 15. Lost your temper while at work & .33 & .44 \\
\hline 16. Neglected to follow your boss's instructions & .65 & .46 \\
\hline 17. Intentionally worked slower than you could have worked & .65 & .40 \\
\hline $\begin{array}{l}\text { 18. Discussed confidential company information with an } \\
\text { unauthorized person }\end{array}$ & .53 & .24 \\
\hline 19. Left work early without permission & .68 & .31 \\
\hline 20. Played a mean prank on someone at work & .42 & .58 \\
\hline 21. Left your work for someone else to finish & .56 & .42 \\
\hline 22. Acted rudely toward someone at work & .49 & .71 \\
\hline 23. Repeated a rumor or gossip about your boss or coworkers & .32 & .30 \\
\hline 24. Made an obscene comment at work & .52 & .61 \\
\hline 25. Used an illegal drug or consumed alcohol on the job & .54 & .26 \\
\hline 26. Put little effort into your work & .68 & .44 \\
\hline 27. Publicly embarrassed someone at work & .30 & .56 \\
\hline 28. Dragged out work in order to get overtime & .50 & .30 \\
\hline Eigenvalue & 8.76 & 2.18 \\
\hline$\%$ variance explained (unrotated factors) & 31.28 & 7.79 \\
\hline$\%$ variance explained (rotated factors) & 29.05 & 5.54 \\
\hline
\end{tabular}

Note. Numbers in boldface indicate dominant factor loadings.

indicate on a 7-point Likert scale ranging from 1 (never) to 7 (daily) the extent to which they had engaged in each of the behaviors in the last year. Respondents also answered several demographic questions. The subsample of 133 respondents were also asked to respond to a variety of self-report attitudinal and behavioral scales. No names or code numbers were associated with the surveys, so respondents were assured that their responses were completely anonymous.

Respondents were asked to mail the completed survey directly back to the researchers. Only those respondents who were currently employed full time were eligible to participate. As such, potential respondents who were unemployed or retired were asked to return the survey uncompleted with an indication of their employment status. In all, 542 surveys were returned; 190 of these were returned uncompleted by potential respondents who were not currently employed full time. In summary, 352 completed, usable surveys were obtained (a response rate of $43 \%$ ). The means, standard deviations, and participation rates for these items are reported in Table 3. It is worth noting that the participation rates for these behaviors were relatively high, but were significantly lower than the participation rates reported in Study 2.

The construct-validation approach used consisted of several stages: (a) demonstrating dimensionality and internal consistency, (b) demonstrating convergent validity by showing high correlations with alternative measures of similar constructs, and (c) demonstrating discriminant validity by showing not-too-high correlations with unrelated constructs (Campbell \& Fiske, 1959; Schwab, 1980). Each of these stages is discussed below.

\section{Phase 1: Dimensionality}

We performed a CFA to cross-validate the two-factor solution obtained in the exploratory factor analysis. LISREL 8 (Jöreskog \& Sörbom, 1993) was used to evaluate the fit of the measurement model. The covariance matrix from the random sample of Toledo residents was used as input for the CFA. We followed Bollen's 
Table 3

Means, Standard Deviations, and Participation Rates of Deviant Workplace Behaviors in Study 3

\begin{tabular}{|c|c|c|c|}
\hline Item & $M$ & $S D$ & Participation rates $^{\mathrm{a}}$ \\
\hline $\begin{array}{l}\text { 1. Worked on a personal matter instead of work for your } \\
\text { employer }\end{array}$ & 2.66 & 1.70 & 60.0 \\
\hline 2. Taken property from work without permission & 1.43 & 0.93 & 20.5 \\
\hline $\begin{array}{l}\text { 3. Spent too much time fantasizing or daydreaming instead of } \\
\text { working }\end{array}$ & 2.39 & 1.75 & 47.3 \\
\hline 4. Made fun of someone at work & 2.93 & 1.95 & 57.3 \\
\hline $\begin{array}{l}\text { 5. Falsified a receipt to get reimbursed for more money than } \\
\text { you spent on business expenses }\end{array}$ & 1.07 & 0.46 & 3.8 \\
\hline 6. Said something hurtful to someone at work & 1.79 & 1.15 & 38.0 \\
\hline $\begin{array}{l}\text { 7. Taken an additional or a longer break than is acceptable at } \\
\text { your workplace }\end{array}$ & 2.50 & 1.77 & 51.8 \\
\hline 8. Made an ethnic, religious, or racial remark or joke at work & 2.17 & 1.65 & 43.0 \\
\hline 9. Come in late to work without permission & 1.69 & 1.22 & 32.7 \\
\hline 10. Littered your work environment & 1.42 & 1.22 & 14.4 \\
\hline 11. Cursed at someone at work & 1.87 & 1.53 & 29.8 \\
\hline 12. Told someone about the lousy place where you work & 2.12 & 1.59 & 35.8 \\
\hline 13. Lost your temper while at work & 2.64 & 1.44 & 69.2 \\
\hline 14. Neglected to follow your boss's instructions & 1.83 & 1.34 & 37.3 \\
\hline 15. Intentionally worked slower than you could have worked & 1.81 & 1.46 & 30.6 \\
\hline $\begin{array}{l}\text { 16. Discussed confidential company information with an } \\
\text { unauthorized person }\end{array}$ & 1.23 & 0.65 & 13.5 \\
\hline 17. Left work early without permission & 1.44 & 1.03 & 21.3 \\
\hline 18. Played a mean prank on someone at work & 1.17 & 0.72 & 7.3 \\
\hline 19. Left your work for someone else to finish & 1.30 & 0.77 & 14.9 \\
\hline 20. Acted rudely toward someone at work & 1.80 & 1.20 & 39.6 \\
\hline 21. Used an illegal drug or consumed alcohol on the job & 1.10 & 0.54 & 3.3 \\
\hline 22. Put little effort into your work & 1.75 & 1.34 & 3.1 \\
\hline 23. Publicly embarrassed someone at work & 1.20 & 0.61 & 10.8 \\
\hline 24. Dragged out work in order to get overtime & 1.12 & 0.61 & 4.7 \\
\hline
\end{tabular}

Note. Responses ranged from 1 (never) to 7 (daily). $N=352$.

a Percentage of respondents who indicated that they had participated in the behavior at least once in the last year.

(1989) recommendation to interpret multiple indexes of fit. We examined LISREL fit statistics, including the chi-square test and the root-mean-square residual (RMSR). Supplementing these indexes, we examined the normed fit index (NFI; Bentler \& Bonnet, 1980), the goodness of fit index (GFI; Jöreskog \& Sörbom, 1986) and the comparative fit index (CFI, Bentler, 1990). The latter two indexes have been shown to be relatively stable in sample sizes smaller than 250 (Hu \& Bentler, 1995).

The CFA showed only a moderate fit for the two-factor model, $\chi^{2}(251, N=143)=422.20, p<.05, \mathrm{RMSR}=.07, \mathrm{GFI}=.80$, $\mathrm{CFI}=.75, \mathrm{NFI}=.56$. However, inspection of the modification indexes, standardized residuals, and factor loadings indicated that a better fit could be obtained by removing five problematic indicators. The items "worked on a personal matter instead of work for your employer," "left work early without permission," "told someone about the lousy place you work," and "left your work for someone else to finish" were dropped from the Organizational Deviance scale. "Lost your temper at work" was dropped from the Interpersonal Deviance scale. Deleting these items improved model fit, $\chi^{2}(147, N=143)=198.37, p<.00$, RMSR $=.05$, $\mathrm{GFI}=.87, \mathrm{CFI}=.90$, and $\mathrm{NFI}=.88$, and resulted in nearly all of the indexes falling within acceptable ranges (Anderson \& Gerbing, 1988).
The 7 interpersonal deviance items were aggregated to form a scale, as were the 12 organizational deviance items. The scales showed acceptable internal consistency, with Cronbach's alpha reliabilities of .81 for the Organizational Deviance scale and .78 for the Interpersonal Deviance scale. The average total score for the Organizational Deviance scale was $19.86,(S D=7.31)$. The average total score for the Interpersonal Deviance scale was 12.98 $(S D=5.97)$. The correlation between these two scales was moderate $\left(r^{2}=.46, p<.01\right)$. This suggests that the two types of workplace deviance are distinct but related. The final scale items are reported in the Appendix.

\section{Phase 2: Convergent and Discriminant Validity Assessment}

A measure has convergent validity to the extent that it covaries with other measures purported to measure the same or similar constructs (Campbell \& Fiske, 1959). To assess the convergent validity of our deviant workplace behavior scales, we first compared the scores on our scales with scores on other scales measuring deviant workplace behaviors or behaviors that are conceptually similar to workplace deviance: modified scales of production deviance and property deviance developed by Hollinger and Clark 
Table 4

Correlations Between Interpersonal and Organizational Deviance Scales and Measures of Similar Behaviors, Theoretically Related Behaviors, and Dissimilar Behaviors

\begin{tabular}{|c|c|c|}
\hline \multirow[b]{2}{*}{ Comparison measure } & \multicolumn{2}{|c|}{ Observed correlations } \\
\hline & $\begin{array}{l}\text { Interpersonal } \\
\text { deviance }\end{array}$ & $\begin{array}{l}\text { Organizational } \\
\text { deviance }\end{array}$ \\
\hline \multicolumn{3}{|l|}{ Similar behaviors } \\
\hline \multicolumn{3}{|l|}{ Hollinger \& Clark $(1982,1983 a, 1983 b)$} \\
\hline Property deviance & $.29 * *$ & $.59 * *$ \\
\hline Production deviance & $.39 *$ & $.70^{* * *}$ \\
\hline \multicolumn{3}{|l|}{ Lehman \& Simpson (1992) } \\
\hline Physical withdrawal & $.23 *$ & $.79 * *$ \\
\hline Psychological withdrawal & $.40 * *$ & $.65^{* *}$ \\
\hline Antagonistic work behavior & $.62 * *$ & $42 * *$ \\
\hline Neglect (Farrell \& Rusbult, 1986) & $.39 * *$ & $.48 * *$ \\
\hline \multicolumn{3}{|l|}{ Theoretically related behaviors } \\
\hline Frustration (Peters, O'Conner, \& Rudolf, 1980) & $.21 *$ & .01 \\
\hline Procedural justice (Niehoff \& Moorman, 1993) & $-.33 * *$ & $-.32 * *$ \\
\hline Distributive justice (Niehoff \& Moorman, 1993) & -.12 & -.08 \\
\hline Interactional justice (Niehoff \& Moorman, 1993) & $-.35 * *$ & -.33 \\
\hline Normlessness (Dean, 1961) & $.21 *$ & .13 \\
\hline Machiavellianism (Christie \& Geis, 1970) & $.39 * *$ & $.26^{*}$ \\
\hline \multicolumn{3}{|c|}{ Citizenship behavior (Podsakoff, MacKenzie, Moorman, \& Fetter, 1990) } \\
\hline Courtesy & $.41^{* *}$ & $-.22 *$ \\
\hline Conscientiousness & $-.28 * *$ & $-.35 * *$ \\
\hline \multicolumn{3}{|l|}{ Dissimilar behaviors } \\
\hline Voice (Farrel \& Rusbult, 1986) & -.09 & -.14 \\
\hline Exit (Farrell \& Rusbult, 1986) & .11 & .17 \\
\hline Loyalty (Farrell \& Rusbult, 1986) & $-.21 *$ & -.13 \\
\hline
\end{tabular}

(1982, 1983a, 1983b), ${ }^{1}$ and scales developed by Lehman and Simpson (1992) to measure physical withdrawal, psychological withdrawal, and antagonistic work behaviors.

Evidence for convergent validity would be demonstrated if scores on these scales were relatively highly correlated with scores on our scales of workplace deviance. Furthermore, we would expect scores on our Organizational Deviance Scale and scores on our Interpersonal Deviance Scale to have differential relationships with scores on these related scales. Specifically, we would expect that scores on the Interpersonal Deviance Scale, compared with scores on the Organizational Deviance Scale, to be more strongly related to scores on the Antagonistic Work Behaviors Scale, as both of these scales include interpersonal behaviors that are potentially harmful to other individuals. Conversely, we would expect scores on the Organizational Deviance Scale, compared with scores on the Interpersonal Deviance Scale, to be more strongly related to scores on the Production Deviance Scale, the Property Deviance Scale, the Psychological Withdrawal Scale, and the Physical Withdrawal Scale, because all of these scales reflect organizationally directed forms of workplace deviance. Such a pattern of findings would also provide some evidence of discriminant validity.

As Table 4 reveals, the relationships between our measures and these similar measures follow our predictions. Scores on the Antagonistic Work Behaviors Scale were more closely related to scores on the Interpersonal Deviance Scale $(r=.62, p<.01)$ than scores on the Organizational Deviance Scale $(r=.42, p<.01)$. Scores on the Psychological Withdrawal Scale, on the other hand, were more closely related to scores on the Organizational Deviance Scale $(r=.65, p<.01)$ than to scores on the Interpersonal Deviance Scale $(r=.40, p<.01)$. Scores on the Physical Withdrawal Scale were also more closely related to the Organizational Deviance Scale $(r=.79, p<.01)$ than to the scores on the Interpersonal Deviance Scale $(r=.23, p<.05)$. Finally, the Property and Production Deviance Scales were also, as expected, more closely related to the Organizational Deviance Scale ( $r=$ $.59, p<.01 ; r=.70, p<.01)$ than to the Interpersonal Deviance Scale $(r=.29, p<.01 ; r=.39, p<.01)$. In summary, scores on our two workplace deviance scales are strongly to moderately correlated with scores on these similar scales in a predictable fashion, exhibiting a mean true score correlation of .50 .

We also examined the relationship between our instruments and theoretically relevant constructs. We would expect these relationships to be moderate, but not as strong as the relationships found between the instrument being validated and other measures purporting to assess the same or similar constructs. Specifically, we looked at the degree of association between the scores on our workplace deviance scales and scores on the following scales: Frustration (Peters, O'Connor, \& Rudolf, 1980); Procedural, Dis-

\footnotetext{
${ }^{1}$ Hollinger \& Clark's (1982) scales of production and property deviance were designed for specific occupations in retail, hospitals, and manufacturing environments. We modified these scales to make them applicable to the wide range of occupations in which the respondents of this study worked.
} 
tributive and Interactional Injustice (Niehoff \& Moorman, 1993); Normlessness (Dean, 1961); Machiavellianism (Christie \& Geis, 1970); and two subscales of Organizational Citizenship Behavior (Podsakoff, MacKenzie, Moorman, \& Fetter, 1990). See Table 4 for the results.

Frustration. Strong relationships have been found between frustration and aggression in general (Berkowitz, 1978; Dollard, Doob, Miller, Mowrer, \& Sears, 1939). In the workplace, frustration has been found to be associated with spreading rumors, vandalism, theft, aggression, and sabotage (Spector, 1975; Storms \& Spector, 1987). As such, we would expect scores on a frustration scale to be associated both with acts directly harmful to the organization (as measured by our Organizational Deviance Scale) as well as with acts directly harmful to other individuals within the organization (as measured by our Interpersonal Deviance Scale).

As predicted, scores on the Frustration Scale were found to be positively associated with scores on the Interpersonal Deviance Scale $(r=.21, p<.05)$ but, contrary to prediction, Frustration Scale scores were not significantly related to scores on the Organizational Deviance Scale $(r=.01, n s)$.

Perceived injustice. Considerations of faimess and justice are extremely important in determining how people will respond in a potentially aggressive setting (Donerstein \& Hatfield, 1982). Furthermore, perceptions of inequity and procedural injustice have been linked to employee theft (Greenberg, 1990, 1993; Siehl, 1987) and vandalism (DeMore, Fisher, \& Baron, 1988; J. D. Fisher \& Baron, 1982). These acts may be a means by which to "get even" with the organization or to retaliate against those individuals who have treated one unfairly (Bies et al., 1997; J. D. Fisher \& Baron, 1982; Greenberg, 1990, 1993). As such, we would expect perceived workplace injustice to be positively related to both of our measures of workplace deviance.

Consistent with our expectations, scores on our interpersonal deviance measure were found to be negatively associated with scores on the scales of Procedural Justice $(r=-.33, p<.01)$ and Interactional Justice $(r=-.35, p<.01)$. Similarly, scores on our measure of organizational deviance were also found to be negatively related to scores on the Procedural Justice Scale $(r=-.32$, $p<.01)$ and to scores on the Interactional Justice Scale $(r=-.33$, $p<.01)$. Contrary to our expectations, however, scores on the Distributive Injustice Scale were not related to scores on either of the deviance scales.

Normlessness. Normlessness refers to the lack of acceptance of social expectations about behavior (Shepard, 1972). According to bonding theory (e.g., Akers, 1973) and social control models of deviance (e.g., Hirschi, 1969), individuals who are "bonded" to a social environment (i.e., individuals who feel attached to social conventions and institutions and who have a commitment to conformity) will be less inclined to engage in deviant acts. As such, we would expect normlessness to be related to workplace deviance. Consistent with our predictions, we found that scores on the Normlessness Scale were related to scores on our Interpersonal Deviance Scale $(r=.21, p<.05)$; however, they were not strongly related to scores on the Organizational Deviance Scale $(r=.13, p=n s)$, although they were in the expected direction.

Machiavellianism. Machiavellianism refers to a person's general strategy for dealing with people, especially the degree to which the individual feels other people are manipulable in interpersonal situations (Christie \& Geis, 1970). We would expect that scores on the Machiavellianism Scale would be more highly related to scores on the Interpersonal Deviance Scale and less related to scores on the Organizational Deviance Scale. We found that scores on the Machiavellianism Scale were related to scores on our Interpersonal Deviance Scale $(r=.39, p<.01)$ and to scores on our Organizational Deviance Scale $(r=.26, p<.05)$.

Organizational citizenship behavior. Organizational citizenship behavior (OCB) refers to extra-role behavior that promotes organizational effectiveness but is not explicitly recognized by an organization's reward system (Organ, 1988, 1990). Organizational deviance is volitional behavior that is potentially harmful to the organization, whereas OCB reflects prosocial, voluntary behavior that is beneficial to the organization. As such, we would expect workplace deviance and OCB to be negatively and moderately related.

We would also expect our two scales of workplace deviance to be more related to some forms of OCB than to others. Specifically, we would expect conscientiousness, a type of OCB defined as discretionary behavior that goes beyond the minimum role requirements of the organization (e.g., attendance, obeying rules, and taking breaks), to be more negatively related to organizational deviance than interpersonal deviance, because organizational deviance includes behaviors such as slowed or reduced work effort. Conversely, we would expect courtesy, OCB aimed at preventing the occurrence of work-related problems for others, to be more negatively related to interpersonal deviance than to organizational deviance because interpersonal deviance reflects behavior that is potentially harmful to one's coworkers.

As predicted, scores on the Conscientiousness Scale were negatively related to scores on our Organizational Deviance Scale ( $r=-.35, p<.01)$ as well as to scores on our Interpersonal Deviance Scale $(r=-.28, p<.01)$. Also as predicted, scores on the Courtesy Scale were more strongly negatively related to scores on our Interpersonal Deviance Scale $(r=-.41, p<.01)$ than to scores on our Organizational Deviance Scale $(r=-.22, p<.05)$.

This pattern of relationships and nonrelationships with related constructs also indicates the discriminant validity of our measure. We expect our measures of interpersonal and organizational deviance to have lower correlations with measures of behaviors that are presumed to be distinct and unrelated. One diverse group of behaviors that should be unrelated to employee deviance behaviors are the diverse responses to dissatisfaction (exit, voice, and loyalty) proposed by Hirschman (1970). This categorization was further revised and expanded by Farrell (1983) and Rusbult, Farrell, Rogers, and Mainous (1988) to include neglect as a fourth category of response to dissatisfaction. Neglect is defined as "passively allowing conditions to deteriorate through reduced interest or effort, chronic lateness or absences, using company time for personal business, or increased error rate" (Rusbult et al., 1988, p. 601). Hence, we would expect interpersonal and organizational deviance to be related to neglect, but not related to exit, voice, and loyalty. The pattern of results gives evidence of discriminant validity. Both the Interpersonal and Organizational Deviance Scales have a relatively strong relationship with the Neglect Scale ( $r=.39, p<.01$ and $r=.48, p<.01$ ), but have much lower correlations with the Exit, Voice, and Loyalty Scales (mean correlation of .14). 


\section{Discussion}

The purpose of this study was to develop a survey instrument that could assess a wide range of deviant workplace behaviors. We believe this goal was accomplished in that considerable support was found for the construct validity of our scales. The first stage of the construct validation process was the assessment of the dimensionality of the deviance instrument. A CFA using maximum likelihood estimation in LISREL 8 provided evidence that the hypothesized two-factor structure fit the data. Two scales of deviance emerged, one reflecting interpersonal deviance and the other reflecting organizationally directed deviance. These results are consistent with prior conceptual approaches that have suggested two distinct forms of workplace deviance, that directed at the organization itself and that directed at its members (Baron \& Neuman, 1996; Giacalone \& Greenberg, 1997; O'Leary-Kelly et al., 1996; Robinson \& Bennett, 1995, 1997; Robinson \& Greenberg, 1999; Skarlicki \& Folger, 1997).

Evidence for the construct validity of our instrument was also found by assessing the relationships between our deviance scales and other measures purported to assess similar constructs. Furthermore, our instrument was found to have moderate relationships with measures of theoretically relevant constructs, such as frustration, perceptions of injustice, and citizenship behavior. Finally, these scales also showed discriminant validity, as they were not highly correlated with measures of unrelated constructs such as exit, voice, and loyalty.

It should be noted that the process of validating a construct is never complete; no measure can ever be said to be validated in any final sense. Only over time and numerous studies can it be argued that the evidence leans toward supporting or not supporting the validity of a particular measure (Nunnally, 1978; Schwab, 1980). The results of this study are a first step, suggesting evidence of the construct validity of these scales. However, future research is necessary to lend additional support to this conclusion.

It is interesting to note the prevalence of the deviant behaviors assessed in this study. The relatively high participation rates contradict common assumptions regarding the frequency of these behaviors as well as the willingness of employees to admit to engaging in these behaviors in self-report measures. It is also interesting to note that whereas the vast majority of the behaviors that we assessed had participation rates above 50\% in Study 2, considerably lower participation rates were reported in Study 3. This difference was unexpected because those in Study 2, with higher participation rates, actually had less anonymity than the sample in Study 3, because those in Study 3 were random mailed-in surveys from the general population. One possible explanation for this finding is demographic differences between the two samples; Study 2 respondents were younger and had less work experience than Study 3 respondents, and thus may be more prone to deviant behavior in the workplace.

The development of these scales of workplace deviance has potentially important implications for future research on deviance in the workplace. To date, empirical research on workplace deviance has been limited. One possible explanation of this shortage of research might be the inherent difficulty in measuring this behavior. The results of this study demonstrate that those employees who completed our unsolicited questionnaire were willing to admit to engaging in socially unacceptable behaviors. Hence, self-report may be useful for assessing deviant behavior in organizations, at least if the respondents are guaranteed anonymity.

The measures developed here may be useful for examining deviance as a more general phenomenon. Most of the limited empirical research on workplace deviance has tended to address only one or two deviant behaviors in isolation, such as theft (Greenberg, 1990, 1993), sabotage (Giacalone, 1990; Taylor \& Walton, 1971), or sexual harassment (Gutek, 1985). These measures will help future researchers take a broader approach to deviance, because these measures cover a range of deviant behaviors. Moreover, measures that take into account families or clusters of behaviors tend to provide more reliable and valid measures of the underlying theoretical construct (C. D. Fisher \& Locke, 1992; Rosse \& Hulin, 1985). Broad measures also aid researchers in better understanding the underlying construct and its many more specific behavioral manifestations (C. D. Fisher \& Locke, 1992; Rosse \& Hulin, 1985), even allowing researchers to generalize their findings to other "surface variables" not included in the scale that reflect the same underlying construct (Rosse \& Hulin, 1985; Roznowski \& Hulin, 1992). Investigating the complete constructs rather than dissecting the constructs into individual behaviors will give researchers a clearer picture of what causes different types of deviant behavior in the workplace, as well as when and under what circumstances these behaviors might be considered substitutable.

Although this study makes numerous contributions, several limitations of this study must also be noted. One possible limitation of this study is that our response rate was only $43 \%$ in Study 3. However, this is a good response rate when compared with response rates obtained in other studies surveying the general population. Moreover, it is likely more representative of the general population of employees than is the more typical study that obtains a high response rate, but from a sample of employees within a single organization.

A second noteworthy limitation is that our study was based entirely on self-report. Although considerable evidence supports the validity of self-reports in general (Spector, 1992), and selfreport has also been found to provide accurate assessments of deviant behaviors in particular (Akers, Massey, Clarke, \& Lauer, 1983; Clark \& Tift, 1966; Lee, 1993; Ones, Viswesvaran, \& Schmidt, -1993), some noteworthy criticisms of this methodology have been raised (Sackett, Burris, \& Callahan, 1989; Sackett \& Harris, 1984). These criticisms center on social desirability biases; critics fear that respondents may attempt to "fake good," thus biasing the results. This fear may, however, be unwarranted, as Ones et al.'s (1993) meta-analysis of integrity measures suggests that self-report criteria tended to result in higher estimates of validity than external measures of deviance. Their explanation is that (a) many deviant behaviors go undetected, hence limiting the validity of external measures, and (b) there is substantial evidence that the correlation between admissions and actual behavior is substantial (Ones, Viswesvaran, \& Schmidt, 1993). Consequently, it is our belief that self-report can be a valid way of assessing the broad variety of deviant behaviors in the workplace, particularly when respondents are assured anonymity.

Researchers must attempt to assure that respondents remain anonymous, or at least assure confidentiality of responses when using these scales, in order to minimize response biases. One must keep in mind that our scales were developed with anonymous respondents outside the workplace. It is difficult to know to what 
extent the results and validity of our scales would be different if the instruments were given to respondents who were not assured anonymity. Even when anonymity is guaranteed, respondents may provide different reports if the self-reports are collected within an organizational setting.

A further limitation of the resulting scales is that they do not include all possible types of deviant behavior. We decided early on to follow the traditional path of scale development, which required us to eliminate items with low variances and low interitem correlations in order to ensure reliability. Upon reflection, we realize that we also made an implicit choice at that stage to create a scale of more common forms of employee deviance. We had to make tradeoffs between ensuring reliability and ensuring that the full range of deviant behaviors were included in our scale. However, we believe we made the right choice for several reasons. First, the approach we took was suitable given our theory that deviant behaviors within a given family are functional substitutes for one another; thus, an employee may engage in one of several types of deviance within a family. This logic suggests that a scale of deviant behavior need not include the complete set of possible manifestations of deviance. Second, the behaviors we eliminated were very rare. Third, had we not eliminated those behaviors, our scale would have lacked reliability and, thus, would be unlikely to be used by others. Thus, although a more inclusive scale may appear more interesting, it is unlikely to have had as much practical value to field researchers.

A final limitation of this study is that, because we have attempted to create a scale that is widely applicable to a range of organizational contexts and occupations, the scale produced here includes only those behaviors commonly found across such contexts. Indeed, in our second study, we assessed and eliminated behaviors that our judges deemed not to be deviant across most organizational contexts. As such, this scale is unable to account for deviant behaviors that are idiosyncratic to specific organizational contexts and occupations. Thus, even though we conceptually define deviance in terms of the particular normative context in which it occurs, our methodology was designed to capture only a subset of the behaviors found in any particular organizational context. Nonetheless, we believe this approach strikes a balance between our belief that deviance is dependent on the social context in which it is defined and our need to produce a generalizable survey instrument appropriate for the rigors of normal science.

In summary, we hope that this instrument proves useful to the future study of workplace deviance, helping to facilitate and encourage the much-needed empirical research into this significant form of organizational behavior.

\section{References}

Akers, R. L. (1973). Deviant behavior: A social learning approach. Belmont, MA: Wadsworth.

Akers, R. L., Massey, J., Clarke, W., \& Lauer, R. M. (1983). Are selfreports of adolescent deviance valid? Biochemical measures, randomized response, and the bogus pipeline in smoking behavior. Social Forces, 62, 234-251.

Anderson, J. G., \& Gerbing, D. W. (1988). Structural equation modeling in practice: A review and recommended two-step approach. Psychological Bulletin, 103, 411-423.

Baron, R. A., \& Neuman, J. H. (1996). Workplace violence and workplace aggression: Evidence on their relative frequency and potential causes. Aggressive Behavior, 22, 161-173.

Bennett, R. J. (1998a). Perceived powerlessness as a cause of employee deviance. In R. Griffin, A. O'Leary Kelley, \& J. Collins, (Eds.), Dysfunctional workplace behavior (pp. 221-239). Greenwich, CT: JAI Press.

Bennett, R. J. (1998b). Taking the sting out of the whip: Reactions to consistent punishments for unethical behaviors. Journal of Applied Social Psychology: Experimental, 4, 1-15.

Bensimon, H. F. (1994). Crisis and disaster management: Violations in the workplace. Training and Development, 28, 27-32.

Bentler, P. M. (1990). Comparative fit indices in structural models. Psychological Bulletin, 107, 238-246.

Bentler, P. M., \& Bonnet, D. G. (1980). Significance tests and goodness of fit in the analysis of covariance structures. Psychological Bulletin, 88, 588-606.

Berkowitz, L. (1978). Whatever happened to the frustration-aggression hypothesis? American Behavioral Scientist, 21, 691-708.

Bies, R. J., Tripp, T. M., \& Kramer, R. M. (1997). At the breaking point: Cognitive and social dynamics of revenge in organizations. In $\mathbf{R}$. A. Giacalone \& J. Greenberg (Eds.), Antisocial behavior in organizations (pp. 18-36). Thousand Oaks, CA: Sage.

Bollen, K. A. (1989). Structural equations with latent variables. New York: Wiley.

Buss, D. (1993). Ways to curtail employee theft. Nation's Business, pp. 36, 38.

Camara, W. J., \& Schneider, D. L. (1994). Integrity tests: Facts and unresolved issues. American Psychologist, 49, 112-119.

Campbell, D., \& Fiske, D. (1959). Convergent and discriminant validation by the multitrait-multimethod matrix. Psychological Bulletin, 56, 81105.

Christie, R., \& Geis, F. L. (1970). Studies in Machiavellianism. San Diego, CA: Academic Press.

Churchill, G. (1988). Basic marketing research. Chicago: Dryden Press.

Clark, J. P., \& Tift, L. L. (1966). Polygraph and interview validation of self-reported deviant behavior. American Sociological Review, 31, 516522.

Dean, D. (1961). Alienation: Its meaning and measurement. American Sociological Review, 25, 753-758.

DeMore, S. W., Fisher, J. D., \& Baron, R. M. (1988). The equity-control model as a predictor of vandalism among college students. Journal of Applied Social Psychology, 18, 80-91.

DeVellis, R. (1991). Scale development: Theory and applications. London: Sage.

Dillman, D. A. (1972). Increasing mail questionnaire response in large samples of the general public. Public Opinion Quarterly, 36, 254-257.

Dillman, D. A. (1978). Mail and telephone surveys: The total design method. New York: Wiley-Interscience.

Dollard, J., Doob, L., Miller, N., Mowrer, O., \& Sears, R. (1939). Frustration and aggression. New Haven, CT: Yale University Press.

Donerstein, E., \& Hatfield, E. (1982). Aggression and inequity. In J. Greenberg \& R. Cohen (Eds.), Equity and justice in social behavior (pp. 309-336). New York: Academic Press.

Farrell, D. (1983). Exit, voice, loyalty, and neglect as responses to job dissatisfaction: A multi-dimensional scaling study. Academy of Management Journal, 26, 596-607.

Farrell, D., \& Rusbult, C. (1986). Measurement of responses to job dissatisfaction: Exit, voice, loyalty and neglect. Unpublished manuscript, Western Michigan University.

Feldman, D. C. (1984). The development and enforcement of group norms. Academy of Management Review, 9, 47-53.

Fisher, C. D., \& Locke, E. A. (1992). The new look in job satisfaction research and theory. In C. J. Cranny, P. C. Smith, \& E. F. Stone (Eds.) Job satisfaction (pp. 165-194). New York: Lexington Books. 
Fisher, J. D., \& Baron, R. M. (1982). An equity-based model of vandalism. Population and Environment, 5, 182-200.

Ford, J. K., MacCallum, R. C., \& Tait, M. (1986). The application of explanatory FA in applied psychology: A critical review and analysis, Personnel Psychology, 39, 291-314.

Fowler, F. J. (1993). Survey research methods. Newbury Park, CA: Sage. Giacalone, R. (1990). Employee sabotage: The enemy within. Supervisory Management, pp. 6-7.

Giacalone, R. A., \& Greenberg, J. (1997). Antisocial behavior in organizations. Thousand Oaks, CA: Sage.

Giacalone, R. A., Riordan, C. A., \& Rosenfeld, P. (1997). In R. Giacalone \& J. Greenberg (Eds.), Antisocial behavior in organizations (pp. 109129). Thousand Oaks, CA: Sage.

Green, G. S. (1997). Occupational crime (2nd ed.). Chicago: Nelson-Hall.

Greenberg, J. (1990). Employee theft as a reaction to underpayment inequity: The hidden cost of paycuts. Journal of Applied Psychology, 75, 561-568.

Greenberg, J. (1993). Stealing in the name of justice: Informational and interpersonal moderators of theft reactions to underpayment inequity. Organizational Behavior and Human Decision Processes, 54, 81-103.

Greenberg, J., \& Scott, K. S. (1996). Why do workers bite the hands that feed them? Employee theft as a social exchange process. In B. M. Staw \& L. L. Cummings (Eds.), Research in organizational behavior (Vol. 18, pp. 111-156). Greenwich, CT: JAI Press.

Gutek, B. A. (1985). Sex in the workplace. San Francisco: Jossey-Bass.

Harper, D. (1990). Spotlight abuse-save profits. Industrial Distribution, 79, 47-51.

Hirschi, T. (1969). Causes of delinquency. Berkeley: University of California Press.

Hirschman, A. O. (1970). Exit, voice, and loyalty: Responses to decline in firms, organizations, and states. Cambridge, MA: Harvard University Press.

Hollinger, R. C., \& Clark, J. P. (1982). Formal and informal social controls of employee deviance. The Sociological Quarterly, 23, 333-343.

Hollinger, R., \& Clark, J. (1983a). Deterrence in the workplace: Perceived certainty, perceived severity, and employee theft. Social Forces, 62, 398-418.

Hollinger, R., \& Clark, J. (1983b). Theft by employees. Lexington, MA: Heath.

Hu, L., \& Bentler, P. M. (1995). Evaluating model fit. In R. H. Hoyle (Ed.), Structural equation modeling: Concepts, issues and applications (pp. 76-99). Thousand Oaks, CA: Sage.

Jöreskog, K. G., \& Sörbom, D. (1986). LISREL IV: Analysis of linear structural relationships by maximum likelihood, instrumental variables and least squares methods (4th ed.). Moorseville, IN: Scientific Software.

Kaplan, H. B. (1975). Self-attitudes and deviant behavior. Pacific Palisades, CA: Goodyear.

Kim, J., \& Mueller, C. (1978). Factor analysis: Statistical methods and practical issues. Newbury Park, CA: Sage.

Lee, R. (1993). Doing research on sensitive topics. London: Sage.

Lehmann, W. E. K., Holcom, M. L., \& Simpson, D. D. (1990). Employee health and performance in the workplace: A survey of municipal employees of a large southwest city (IBR tech. rep.). Fort Worth: Texas Christian University, Institute of Behavioral Research.

Lehman, W., \& Simpson, D. (1992). Employee substance abuse and on-the-job behaviors. Journal of Applied Psychology, 77, 309-321.

McGurn, X. (1988). Spotting the thieves who work among us. Wall Street Joumal, p. 16a.

Murphy, K. R. (1993). Honesty in the workplace. Belmont, CA: Brooks/ Cole.

Northwestern Life Insurance Company. (1993). Fear and violence in the workplace. Minneapolis, MN: Author

Niehoff, B. P., \& Moorman, R. H. (1993). Justice as a mediator of the relationship between methods of monitoring and organizational citizenship behavior. Academy of Management Journal, 36, 528-556.

Nunnally, J. C. (1978). Psychometric theory. New York: McGraw-Hill.

O'Leary-Kelly, A. M., Griffin, R. W., \& Glew, D. J. (1996). Organizationmotivated aggression: A research framework. Academy of Management Review, 21, 225-253.

Ones, D. S., Viswesvaran, C., \& Schmidt, F. L. (1993). Meta-analysis of integrity test validities: Findings and implications for personnel selection and theories of job performance. Journal of Applied Psychology, 78, 679-703.

Organ, D. W. (1988). Organizational citizenship behavior. Lexington, MA: Lexington Books.

Organ, D. W. (1990). The motivational basis of organizational citizenship behavior. In L. L. Cummings \& B. M. Staw (Eds.), Research in organizational behavior (pp. 43-72). Greenwich, CT: JAI Press.

Peters, L. J., O'Connor, E. J., \& Rudolf, C. J. (1980). The behavioral and affective consequences of situational variables relevant to performance settings. Organizational Behavior and Human Performance, 25, 79-96.

Podsakoff, P. M., MacKenzie, S., Moorman, R. H., \& Fetter, R. (1990). Transformational leader behaviors and their effects on followers' trust in leader, satisfaction, and organizational citizenship behaviors. Leadership Quarterly, 1, 107-142.

Robinson, S., \& Bennett, R. (1995). A typology of deviant workplace behaviors: A multi-dimensional scaling study. Academy of Management Journal, 38, 555-572.

Robinson, S., \& Bennett, R. (1997). Workplace deviance: Its definition, its manifestations, and its causes. Research on Negotiations in Organizations, 6, 3-27.

Robinson, S., \& Greenberg, J. (1999). Employees behaving badly: Dimensions, determinants and dilemmas in the study of workplace deviance. In D. M. Rousseau \& C. Cooper (Eds.), Trends in organizational behavior (Vol. 5, pp. 1-23). New York: Wiley.

Rosse, J., \& Hulin, C. (1985). Adaptation to work: An analysis of employee health, withdrawal, and change. Organizational Behavior and Human Decision Processes, 36, 324-247.

Roznowski, M., \& Hulin, C. (1992). The scientific merit of valid measures of general constructs with special reference to job satisfaction and job withdrawal. In C. J. Cranny, P. C. Smith, \& E. F. Stone (Eds.), Job satisfaction (pp. 123-163). New York: Lexington Books.

Rusbult, C., Farrell, D., Rogers, G., \& Mainous, A. (1988). Impact of exchange variables on exit, voice, loyalty, and neglect: An integrative model of responses to declining job satisfaction. Academy of Management, 31, 599-627.

Sackett, P. R., Burris, L. R., \& Callahan, C. (1989). Integrity testing for personnel selection: An update. Personnel Psychology, 42, 491-528.

Sackett, P. R., \& Harris, M. M. (1984). Honesty testing for personnel selection; A review and critique. Personnel Psychology, 32, 221-245.

Schwab, D. P. (1980). Construct validity in organizational behavior. In B. M. Staw \& L. L. Cummings (Eds.), Research in organizational behavior (pp. 3-43). Greenwich, CF: JAI Press.

Shepard, J. M. (1972). Alienation as a process: Work as a case in point. The Sociological Quarterly, 13, 161-173.

Siehl, E. W. (1987). Garment workers: Perceptions of inequity and employee theft. British Journal of Criminology, 27, 174-190.

Skarlicki, D. P., \& Folger, R. (1997). Retaliation in the workplace: The roles of distributive, procedural, and interactional justice. Journal of Applied Psychology, 82, 416-425.

Snyder, N. H., Blair, K. E., \& Arndt, T. (1990). Breaking the bad habits behind time theft. Business, 40(4), 31-33.

Spector, P. (1975). Relationships of organizational frustration with reported behavioral reactions of employees. Journal of Applied Psychology, 60, 635-637.

Spector, P. (1992). A consideration of the validity and meaning of selfreport measures of job conditions. In C. L. Cooper \& I. T. Robertson 
(Eds.), International review of industrial and organizational psychology (pp. 123-151). Chichester, England: Wiley.

Storms, P., \& Spector, P. (1987). Relationships of organizational frustration with reported behavioral reactions: The moderating effect of locus of control. Journal of Occupational Psychology, 60, 227-234.

Taylor, L., \& Walton, P. (1971). Industrial sabotage: Motives and meanings. In S. Cohen (Ed.), Images of deviance (pp. 219-245). Middlesex, England: Penguin Books.
Turner, D. L., \& Stephenson, R. G. (1993, February). The lure of whitecollar crime. Security Management, pp. 57-58.

Webb, S. L. (1991). Step forward: Sexual harassment in the workplace. New York: MasterMedia.

Williams, L. J., \& Andersen, S. E. (1991). Job satisfaction and organizational commitment as predictors of organizational citizenship behavior and in-role behaviors. Journal of Management, 17, 601617.

\section{Appendix}

Final Interpersonal and Organizational Deviance Scale Items

Made fun of someone at work
Said something hurtful to someone at work
Made an ethnic, religious, or racial remark at work
Cursed at someone at work
Played a mean prank on someone at work
Acted rudely toward someone at work
Publicly embarrassed someone at work
Taken property from work without permission
Spent too much time fantasizing or daydreaming instead of working
Falsified a receipt to get reimbursed for more money than you spent on business expenses
Taken an additional or longer break than is acceptable at your workplace
Come in late to work without permission
Littered your work environment
Neglected to follow your boss's instructions
Intentionally worked slower than you could have worked
Discussed confidential company information with an unauthorized person
Used an illegal drug or consumed alcohol on the job
Put little effort into your work
Dragged out work in order to get overtime

Received November 22, 1996

Revision received June 29, 1999

Accepted July 6, 1999 